\title{
Effects of continual burial by sediment on seedling emergence and morphology of Suaeda salsa in the coastal marsh of the Yellow River estuary, China
}

\author{
Zhigao Sun $^{\mathrm{a}, *}$, Hongli Song ${ }^{\mathrm{a}, \mathrm{b}}$, Jingkuan Sun ${ }^{\mathrm{c}}$, Wenguang Sun ${ }^{\mathrm{a}}$

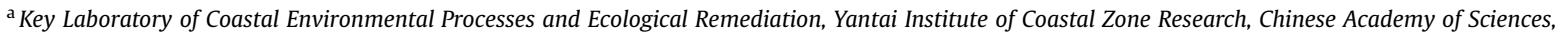 \\ Yantai, Shandong 264003, PR China \\ ${ }^{\mathrm{b}}$ University of Chinese Academy of Sciences, Beijing 100049, PR China \\ ' Shandong Provincial Key Laboratory of Eco-Environmental Science for Yellow River Delta, Binzhou University, Binzhou, Shandong 256603, PR China
}

\section{A R T I C L E I N F O}

\section{Article history:}

Received 23 July 2013

Received in revised form

10 January 2014

Accepted 13 January 2014

Available online 5 February 2014

\section{Keywords:}

Continual burial

Morphological trait

Seedling emergence

Suaeda salsa

Yellow River estuary

\begin{abstract}
A B S T R A C T
A greenhouse study was conducted to determine the impacts of continual burial on seedling emergence and morphology of Suaeda salsa, a pioneer species in the coastal marsh of the Yellow River estuary. From May to June 2012, seeds of $S$. salsa were artificially buried to depths of $0 \mathrm{~cm}$ (no burial), $2 \mathrm{~cm}$ (burial of $1 \mathrm{~mm} \mathrm{~d}^{-1}$ ), $4 \mathrm{~cm}$ (burial of $2 \mathrm{~mm} \mathrm{~d}^{-1}$ ), $6 \mathrm{~cm}$ (burial of $3 \mathrm{~mm} \mathrm{~d}^{-1}$ ), $8 \mathrm{~cm}$ (burial of $4 \mathrm{~mm} \mathrm{~d}^{-1}$ ) and $10 \mathrm{~cm}$ (burial of $5 \mathrm{~mm} \mathrm{~d}^{-1}$ ) in plastic pots filled with unsterilized sediment. Results showed that the percent emergence of seedlings had a significantly negative correlation with continual burial depth $(p<0.001)$. A large percentage of seedlings emerged from 2,4 and $6 \mathrm{~cm}$ burial depths, with the highest emergence $(56.00 \pm 6.60 \%)$ occurring from $2 \mathrm{~cm}$ depth. The shortest emergence time occurred at $4 \mathrm{~cm}$ burial depth and seeds buried at $10 \mathrm{~cm}$ depth took longer to emerge than those at other depths. At shallow or moderate burials, a stimulatory effect on seedling height, stem diameter, number and length of branch, taproot length and dry mass were observed. With increasing burial depth, root-mass and leaf-mass ratios generally increased while stem-mass ratio decreased. Sediment burial also stimulated part of the hypocotyl below the sediment to form adventitious roots, implying that $S$. salsa seedlings had a special adaptive strategy in response to the rapid and dynamic burial environment in the coastal marsh of the Yellow River estuary. The use of thin-layer continual burial $\left(1-2 \mathrm{~mm} \mathrm{~d}^{-1}\right)$ to promote the emergence of S. salsa seedlings in degraded marsh was feasible, and our study provided another way for the restoration of $S$. salsa marsh during the initial stage of seedling establishment and laid a good foundation for the scientific decision-making and management of restoration project at a large scale.
\end{abstract}

(ㄷ) 2014 Elsevier Ltd. All rights reserved.

\section{Introduction}

Plants growing on coastal marshes are exposed to a number of extreme conditions, such as high wind velocities, drastic temperature fluctuations, high potential evapotranspiration, salt spray, low levels of sediment nutrients, inundation by seawater and burial in sediment (Baldwin and Maun, 1983; Maun, 1998; Deng et al., 2008). Among them, sediment burial has been recognized as a major selective force in the evolution of seed germination, seedling emergence, seedling establishment and survivorship of seedlings and adult plants (Maun, 1994). Depending on the magnitude of different disturbing agents (storms, tidally induced sediment

\footnotetext{
* Corresponding author. Tel.: +86 (0)535 2109121; fax: +86 (0)535 2109000.

E-mail address: zgsun@yic.ac.cn (Z. Sun).
}

movement and bioturbation) in coastal marshes, the sediment can be disrupted to various depths (Chandrasekaral and Frid, 1998), and the different sediment disturbances may result in the seeds, seedlings and adult plants being directly damaged and killed or buried within the sediment to different extent. Simultaneously, plants evolve a variety of adaptations (such as higher seedling height, longer hypocotyl and root system, and increased dry mass accumulation) that allow survival, growth and reproduction under relatively stressful and variable conditions (Maun and Riach, 1981; Maun and Lapierre, 1986; Redmann and Qi, 1992; Maun, 1994; Thampanya et al., 2002; Deng et al., 2008; Li et al., 2011; Wen et al., 2012).

The germination of seeds is related to the depth at which seeds are buried (Harper and Benton, 1966; Zhang and Maun, 1994). Burial at shallow depths generally stimulates more germination and emergence (Maun, 1994) and has significant stimulation to the 
morphological traits of plants (such as height, leaf area and thickness, seed production, dry mass, length of leaf, stem, taproot, hypocotyl and internode, number of leaves, internodes, branches and tillers) (Disraeli, 1984; Maun and Lapierre, 1986; Zhang and Maun, 1990; Redmann and Qi, 1992; Chen and Maun, 1999; Thampanya et al., 2002; Deng et al., 2008), which is presumably due to the major changes in sediment nutrient status, temperature, microorganism composition, mycorrhizal fungi and sediment aeration (Maun, 1998). However, excessive burial may prevent seedlings from emerging above the sediment surface and thus affect survival, because pre-emergence mortality results from a cessation of seedling growth before it reaches the sediment surface or the seeds are unable to germinate due to lack of oxygen, light and temperature fluctuation (Maun and Riach, 1981; Zhang and Maun, 1990). Thus, there is a threshold of sediment burial depth for each plant to maximize seedling emergence and subsequent growth. Below the threshold level of burial, the emergence and growth of seedlings are stimulated by sediment burial. As the level of burial increases over the threshold, seedling emergence and growth are seriously constrained (Zhang and Maun, 1994; Maun et al., 1996).

There has been intense and increasing interest in understanding the response of seedlings to burial because burial is an important factor controlling the distribution and composition of plants in different communities (van der Valk, 1974; Maun and Lapierre, 1986; Leishman and Westoby, 1994; Chen and Maun, 1999; Thampanya et al., 2002; Li et al., 2006; Deng et al., 2008; Mou and Sun, 2011). Studies on the responses of seedling emergence and growth to burial have been widely reported, which mainly focused on arid/semi-arid dune (Maun and Lapierre, 1986; Leishman and Westoby, 1994; Huang et al., 2004; Li et al., 2006), coastal/lacustrine dune (Zhang and Maun, 1994; Cheplick and Grandstaff, 1997; Chen and Maun, 1999), coastal marsh (Deng et al., 2008; Mou and Sun, 2011) and mangrove swamp (Lee et al., 1996; Terrados et al., 1997; Thampanya et al., 2002). Overall, previous studies mostly focus on single one-time burial, while information on the tolerance or stimulation responses to continual burial episodes is lacking. Actually, plants in natural habitats are most often exposed to dynamic and stochastic disturbance events, and the chances of seedling emergence may be much higher since dynamic burial generally maintains a low-stress environment around seeds compared to single one-time burial (Maun et al., 1996).

The Yellow River is well known as a sediment-laden river. Every year, approximately $1.05 \times 10^{7}$ tons of sediment is carried to the estuary and deposited in the slow flowing landform, resulting in vast floodplain and special marsh landscape (Xu et al., 2002). Sediment deposition is an important process in the formation and development of coastal marsh in the Yellow River Delta. The deposition rate of sediment in the Yellow River not only affects the formation rate of coastal marsh, but also influences the water or salinity gradients and the succession of plants from the land to the sea. Suaeda salsa is the most prevalent plant in the coastal marsh of the Yellow River estuary. It generally germinates in late April, blooms in July, matures in late September and completely dies in late November (Gu, 1998). As a pioneer plant, it is often affected by the sediment of tide physical disturbance, which is generally dependent on prevailing wind velocities. Although $S$. salsa can tolerate high salinity habitat, there is an optimum ecological threshold of sediment salinity $\left(12.71 \mathrm{~g} \mathrm{~kg}^{-1}\right.$ ) for the plants (Cui et al., 2008). If the salinity level exceeds the threshold, the plants will not grow better and generally exhibit varying degrees of degradation. As the coastal mash is frequently supplied by freshwater, the sediment salinity can be maintained around the optimum ecological threshold, which is favorable for the growth of S. salsa. It was reported that the annual runoff of the Yellow River showed great inter-annual changes since the 1980s. The runoff reached the maximum value of 49.1 billion $\mathrm{m}^{3}$ in 1983 and then decreased and fluctuated at 20.0 billion $\mathrm{m}^{3}$ in the following several years. From 1997 to 2002, the annual runoff was mainly below 10.0 billion $\mathrm{m}^{3}$ (Cui et al., 2009). The low flows of the Yellow River led to a significant decrease in freshwater supply to the estuary and the $S$. salsa marshes near the estuary exhibited seriously degraded status. In order to restore degraded marshes, the 'water and sand regulation project' (WSRP) was initiated by the nation in 2002. The purpose of the WSRP was to increase the supply of freshwater and sediment for the Yellow River estuary by discharging the water in Xiaolangdi Reservoir and scouring the sediment in the reservoir and riverbed (Cui et al., 2009). During the WSRP (from June to July in each year), the river water frequently flooded the $S$. salsa marshes near the estuary and resulted in considerable sediment deposition (approximately 5-6 cm thick), which continually and significantly influenced seedling emergence and growth (Mou, 2010). However, little is known about the impacts of continual burial on seedling emergence and morphology in the coastal marsh of the Yellow River estuary.

In this paper, the effects of continual burial on seedling emergence and principal morphological traits of $S$. salsa were investigated experimentally. The primary objectives of this study were $i$ ) to examine whether sediment burial caused by continual burial episodes would have great impacts on seedling emergence, $i i)$ to determine the different influences of continual burial on morphological traits, and iii) to investigate the feasible of continual burial in restoration and management of degraded marsh.

\section{Materials and methods}

\subsection{Study site}

This study was conducted in a greenhouse in the Shandong Key Laboratory for Eco-Environmental Science of the Yellow River Delta in Binzhou University. The sediment used in this experiment was sampled from the coastal marsh of the Yellow River estuary [sample depth: $15 \mathrm{~cm}$; sediment salinity (water extracted salinity): $1.49 \pm 0.27 \%(n=5)]$, which is located in the Nature Reserve of Yellow River Delta $\left(37^{\circ} 35^{\prime} \mathrm{N} \sim 38^{\circ} 12^{\prime} \mathrm{N}, 118^{\circ} 33^{\prime} \mathrm{E} \sim 119^{\circ} 20^{\prime} \mathrm{E}\right)$ in Dongying City, Shandong Province, China. The nature reserve is of typical continental monsoon climate with distinctive seasons. The average annual temperature is $12.1^{\circ} \mathrm{C}$ and the frost-free period is $196 \mathrm{~d}$. Annual evaporation is $1962 \mathrm{~mm}$ and annual precipitation is $551.6 \mathrm{~mm}$, with about 70 percent of precipitation occurring between June and August. The soils in the study area are dominated by intrazonal tide soil and salt soil, and the main vegetations include Phragmites australis, S. salsa, Triarrhena sacchariflora, Myriophyllum spicatum and Tamarix chinensis (Sun et al., 2012). Coastal marsh is the main marsh type, with an area of $964.8 \mathrm{~km}^{2}$, accounting for $63.06 \%$ of the total area of the Yellow River Delta (Cui et al., 2009). The tide in the intertidal zone of the Yellow River estuary is irregular semidiurnal tide and the mean tidal range is 0.73-1.77 $\mathrm{m}$ (Li et al., 1991). As the pioneer plant in coastal marsh, S. salsa is often affected by the sediment deposition of tidal disturbance, bioturbation and Yellow River flooding during the WSRP. The sedimentary rate in the S. salsa marsh is about 9$10 \mathrm{~cm} \mathrm{yr}^{-1}$, and approximately $6-7 \mathrm{~cm}$ occurs at the seedling stage due to the significant influences of both tidally induced sediment and WSRP (Mou, 2010).

\subsection{Experimental method}

Seeds of S. salsa were collected in the fall of 2011 from four typical regions of the Yellow River estuary. Seeds were collected 
from multiple individuals (about 800 individuals) in each region and mixed together. Seeds were cleaned, dried at room temperature for $2-3$ weeks, then stored at $8{ }^{\circ} \mathrm{C}$ under dry, dark conditions. The experiment was begun on May 10, 2012. According to the above-mentioned sedimentary rate in the coastal marsh of the Yellow River estuary, a depth of $10 \mathrm{~cm}$ was chosen as the maximum depth of burial. Counted seeds (20 each) were artificially buried to depths of $0 \mathrm{~cm}$ (no burial), $2 \mathrm{~cm}$ (burial of $1 \mathrm{~mm} \mathrm{~d}^{-1}$ ), $4 \mathrm{~cm}$ (burial of $2 \mathrm{~mm} \mathrm{~d}^{-1}$ ), $6 \mathrm{~cm}$ (burial of $3 \mathrm{~mm} \mathrm{~d}^{-1}$ ), $8 \mathrm{~cm}$ (burial of $4 \mathrm{~mm} \mathrm{~d}^{-1}$ ) and $10 \mathrm{~cm}$ (burial of $5 \mathrm{~mm} \mathrm{~d}^{-1}$ ) in plastic pots (26 cm in diameter, $30 \mathrm{~cm}$ in height, the distances between seeds were about 5-6 cm) filled with unsterilized sediment (sediments were mixed homogeneously as possible before being used), with 20 days in total. There were five replicates per treatment. The drainage outlet at the bottom of the pots was covered with strips of nylon mesh to prevent the loss of sediment while allowing drainage of excess water. Sediment was poured into each plastic pot up to the lower mark (near the top) and moistened, then the seeds $(n=20)$ were placed on the sediment surface and additional sediment was added to the pots according to different burial depths every day.

During the experiment, the pots were regularly watered with tap water, and every two days with seawater in order to better simulate field conditions and avoid excessive salinity accumulating in sediment as seawater was used alone. The salinity of the sediment in each pot was monitored daily and adjusted to the field condition every four days. Temperature in the greenhouse was maintained at $23{ }^{\circ} \mathrm{C}$ during the day ( $16 \mathrm{~h}$ photoperiod) and $14{ }^{\circ} \mathrm{C}$ at night [approximating the average temperature in May (22.5 ${ }^{\circ} \mathrm{C}$ during the day and $13.6^{\circ} \mathrm{C}$ at night)]. Emerged seedlings were counted daily. Seedling emergence was defined as the first appearance of a seedling at the sediment surface. After 20 days of burial when there was no other seedlings emerged, the heights of seedlings were determined on May 31 (21 days), June 5 (26 days), June 10 (31 days), June 15 (36 days), June 20 (41 days) and June 25 (46 days), respectively. Seedling heights were measured from sediment surface to seedling top, which was similar with the measurement reported in Li et al. (2006) and Zhao et al. (2007). Since seedlings were small and had no branch during the burial, stem diameter, number and length of branch were not measured. After 31 days (June 10), stem diameter, number and length of branch were measured every 5 days. After 46 days of seedling emergence and growth in the greenhouse (June 25), the experiment was terminated and all seedlings were harvested. At harvest, seedlings were dug out by hand and trowel, and care was taken to collect as many roots belonging to seedling as possible. Seedlings were then taken to the laboratory and stem diameter, number and length of branch, hypocotyl and taproot length were measured. After seedlings were separated into root, stem and leaf, each fraction was weighed after drying at $80^{\circ} \mathrm{C}$ for $48 \mathrm{~h}$.

\subsection{Calculation}

The absolute height growth rate $\left(A H G R, \mathrm{~mm} \mathrm{~d}^{-1}\right)$ and relative height growth rate $\left(R H G R, \mathrm{~mm} \mathrm{~cm} \mathrm{~cm}^{-1} \mathrm{~d}^{-1}\right)$ of seedlings were calculated by the following equations (Zhao et al., 2007):

$\mathrm{AHGR}=\frac{H_{2}-H_{1}}{T_{2}-T_{1}} \quad$ RHGR $=\frac{H_{2}-H_{1}}{H_{1}\left(T_{2}-T_{1}\right)}$

where $H_{1}, H_{2}$ were heights after sowing for 20 days and at harvest, respectively, and $T$ was time in days.

\subsection{Statistical analysis}

Descriptive statistics analysis of experimental data was performed using SPSS Version 11.0 statistical software package. The results were presented as means of the replications, with standard error (S.E). The relationship between percent emergence and continual burial depth was analyzed by correlation analysis.

\section{Results}

\subsection{Effects of continual burial on seedling emergence}

Seedling emergence occurred earliest for the seeds from $4 \mathrm{~cm}$ burial depth (days to the first emergence, $2.0 \mathrm{~d}$ ), and seeds buried at $10 \mathrm{~cm}$ depth took longer to emerge $(4.0 \mathrm{~d})$ than those at other depths (Fig. 1). The higher percent emergence of seedlings and shorter emergence course generally occurred at 2, 4 and $6 \mathrm{~cm}$ burial depths, while at $10 \mathrm{~cm}$ depths, the percent emergence was lower and the emergence course was longer (Fig. 1). A large percentage of seedlings emerged from 2, 4 and $6 \mathrm{~cm}$ burial depths, with the highest emergence $(56.00 \pm 6.60 \%)$ occurring from $2 \mathrm{~cm}$ depth. Seedling emergences occurring from 0 and $8 \mathrm{~cm}$ burial depths were approximated, while seedlings emerged from $10 \mathrm{~cm}$ depth was the lowest $(16.00 \pm 3.67 \%$ ) (Fig. 2). Except for $0 \mathrm{~cm}$ burial treatment, the mean percent emergence of seedlings at other treatments was negatively correlated with burial depth $(r=-0.976, p<0.001)$.

\subsection{Effects of continual burial on seedling morphology}

\subsubsection{Seedling height}

Seedling heights were generally high at 2, 4 and $6 \mathrm{~cm}$ burial depths, and the lowest value occurred at $10 \mathrm{~cm}$ depth. At the $21 \mathrm{st}$ day, seedling heights were approximated at $0,2,4$ and $6 \mathrm{~cm}$ depths, but higher than the values at 8 and $10 \mathrm{~cm}$ depths. At the 26th, 31st and 36th day, the heights at 2, 4 and $6 \mathrm{~cm}$ burial depths greatly surpassed the values at 0,8 and $10 \mathrm{~cm}$ depths. Although seedling height at $4 \mathrm{~cm}$ burial depth was the highest at the $41 \mathrm{st}$ and $46 \mathrm{th}$ day, the values at 6 and $8 \mathrm{~cm}$ burial depths surpassed the ones at $2 \mathrm{~cm}$ burial depth (Fig. 3).

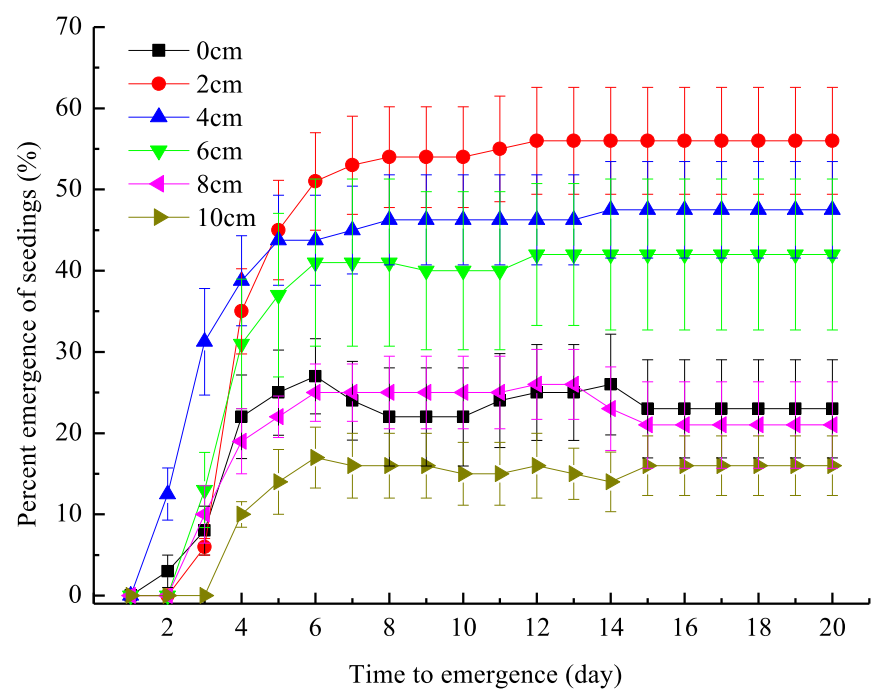

Fig. 1. Emergence course of seedlings of Suaeda salsa from different continual burial depths. Vertical lines represent one standard error. 


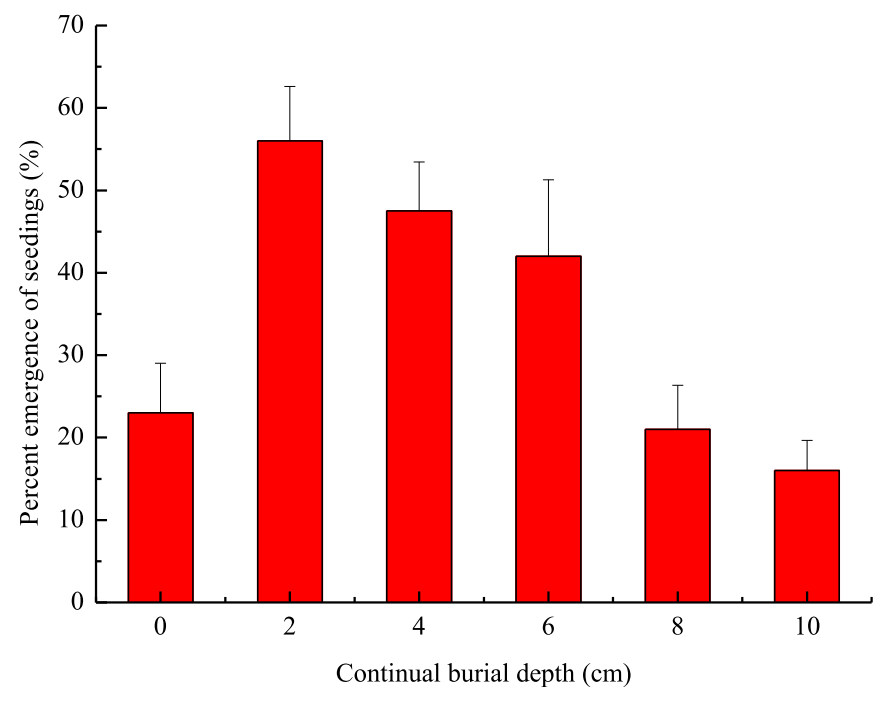

Fig. 2. Mean $( \pm$ SE) percent emergence of seedlings of Suaeda salsa from different continual burial depths.

\subsubsection{Height growth rate}

The AHGRs of seedlings at 2, 4, 6 and $8 \mathrm{~cm}$ burial depths were higher than those at 0 and $10 \mathrm{~cm}$ depths (Fig. 4A), while the RHGRs of seedlings increased with increasing burial depth (Fig. 4B). The lowest $A H G R$ and $R H G R$ were observed at $0 \mathrm{~cm}$ burial depth, while the highest values occurred at 8 and $10 \mathrm{~cm}$ depths, respectively. Although seedling height at $10 \mathrm{~cm}$ depth was less than those at other depths, the highest RHGR occurred at $10 \mathrm{~cm}$ burial depth, indicating that seedlings at $10 \mathrm{~cm}$ depth had the highest growth potential.

\subsubsection{Stem diameter and branch of seedlings}

Stem diameter generally increased with increasing burial depth except for $10 \mathrm{~cm}$ burial (Fig. 5A). The number and length of seedling branch emerging from $0 \mathrm{~cm}$ burial depth were higher than those from $10 \mathrm{~cm}$ depth, but much lower than those from 2, 4, 6 and $8 \mathrm{~cm}$ depths (Fig. 5B,C). Although the number of seedling branch was the highest at $4 \mathrm{~cm}$ burial depth, the value at $8 \mathrm{~cm}$ depth surpassed those at 2 and $6 \mathrm{~cm}$ depths. At the 31st and 36th day, the lengths of seedling branch were the highest at $6 \mathrm{~cm}$ burial depth, while at the $41 \mathrm{st}$ and 46 th day, the values at $4 \mathrm{~cm}$ depth surpassed those at $6 \mathrm{~cm}$ depth.

\subsubsection{Hypocotyl and taproot of seedlings}

Except for $10 \mathrm{~cm}$ burial, the lengths of seedling hypocotyl decreased with increasing burial depth (Fig. 6A) while those of taproot increased (Fig. 6B). Since the belowground parts of S. salsa almost were roots during the experiment, it was concluded that part of the hypocotyls below the sediment developed into adventitious roots.

\subsection{Effects of continual burial on seedling dry mass and dry mass allocation}

At shallow burial depths, the dry mass increased with increasing burial depth and the highest values occurred at $4 \mathrm{~cm}$ depth (Fig. 7). While at moderate and deep burial depths, the dry mass decreased with increasing burial depth, with the lowest values occurring at $10 \mathrm{~cm}$ depth. Although the dry mass of seedlings and their different parts of the $6 \mathrm{~cm}$ burial treatment were less than those of the $4 \mathrm{~cm}$ burial treatment, the values were still higher than those of the other treatments. The dry mass allocations to root, stem and leaf were altered by burial depth and with increasing burial depth, leafmass and root-mass ratios increased from $69.45 \%$ to $71.95 \%$ and from $5.36 \%$ to $6.88 \%$, respectively, while stem-mass ratio decreased from $25.19 \%$ to $21.18 \%$.

\section{Discussion}

\subsection{Seedling emergence at different continual burial depths}

As the pioneer species in the coastal marsh of the Yellow River estuary, seeds of $S$. salsa above the sediment may be easily buried by sediment to various depths during establishment in late spring. Continual burial by tide-deposited sediment (Cheplick and Grandstaff, 1997) or flood-deposited sediment during the WSRP of the Yellow River (Cui et al., 2009) may be a critical episode for $S$. salsa seedling emergence and establishment in such habitats. Seed burial has both positive and negative consequences for seedling emergence, so there is an optimal range of burial depth to maximize the likelihood of seedling emergence and subsequent

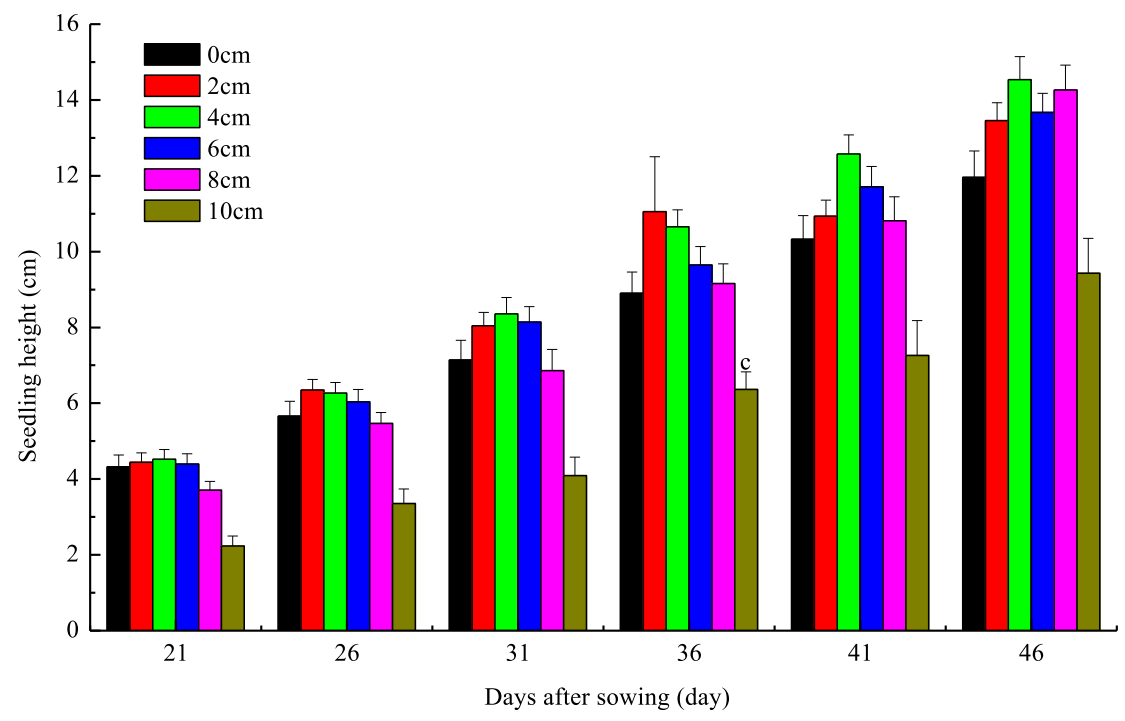

Fig. 3. Mean height $( \pm$ SE) of seedlings of Suaeda salsa at different continual burial depths. 

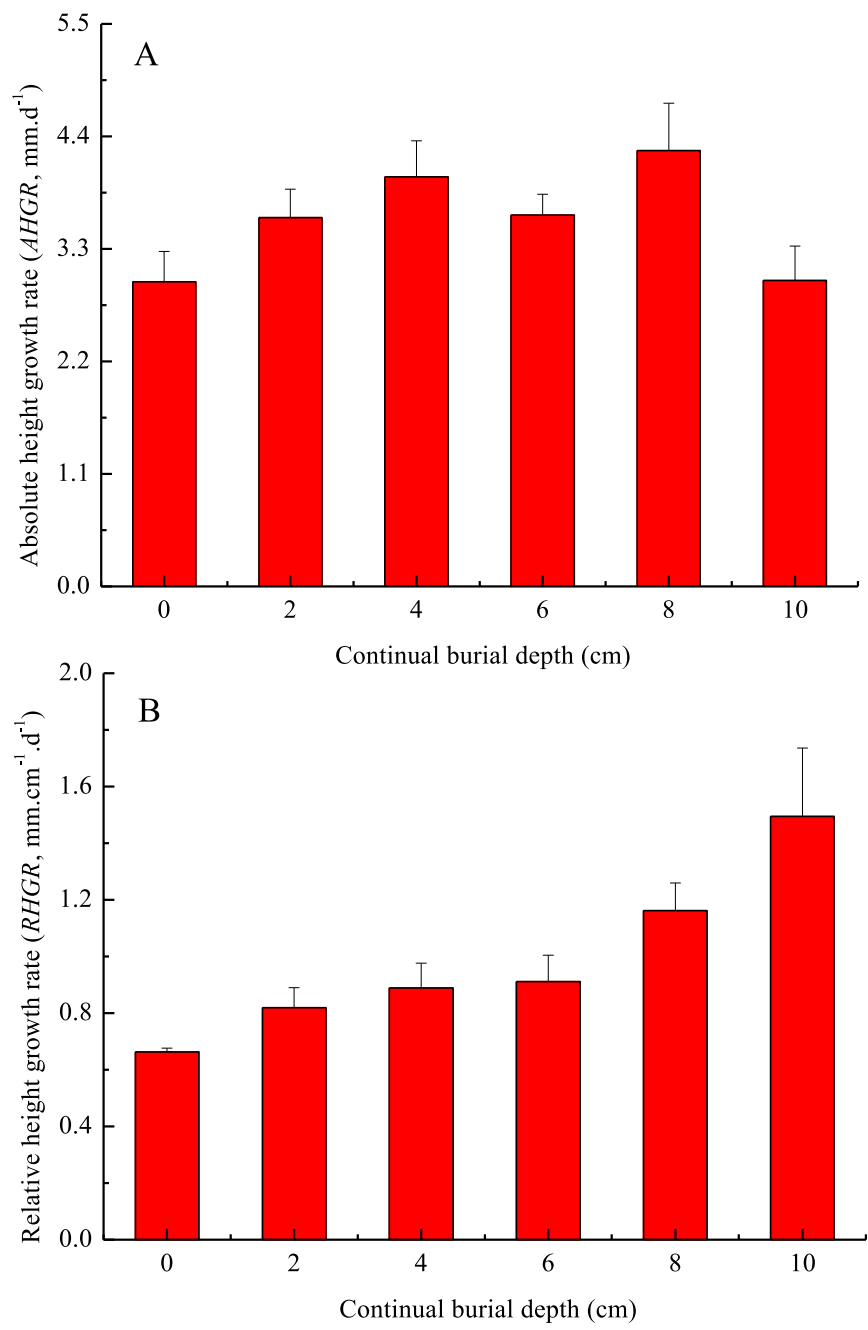

Fig. 4. Mean $( \pm \mathrm{SE})$ absolute height growth rate $(A H G R, \mathrm{~A})$ and relative height growth rate $(R H G R, B)$ of seedlings of Suaeda salsa at different continual burial depths after 46 days.

growth (Li et al., 2006). The most obvious negative consequence is burial so deep that seed germination is prevented. Germination sometimes occurs with deep burial, but seed energy reserves may be exhausted before seedlings reach the sediment surface, which results in seedling death. The continual burial experiment of $S$. salsa showed that a large percentage of seedlings emerged from shallow and moderate burial depths (2, 4 and $6 \mathrm{~cm}$ ), while deeper burial greatly inhibited seedling emergence. With increasing burial depth, the percent emergence of seedlings decreased and it was negatively correlated with continual burial depth. Similar results were also reported by some single one-time burial experiments (Maun and Lapierre, 1986; Chen and Maun, 1999). For one thing, different continual burials might gradually change the physiological requirements and structural limitations of seeds and alter the microenvironment factors (such as temperature, humidity, oxygen, light and nutrients) surrounding the seeds (Perry, 1984), which significantly affects seeds germination. For another, the energy reserved in seeds significantly influences seedling emergence (Weis, 1982), and there was a positive correlation between seed mass and seedling emergence both within and between plant species (Yanful and Maun, 1996). A bigger seed means more energy reserves and greater tolerance to a wide range of environmental stresses (Weller, 1985; Leishman and Westoby, 1994). In this study, because $S$. salsa seeds were very small (about $1 \mathrm{mg}$ per seed), the energy reserved in seeds might not be sufficient to enable seedlings to emerge above the sediment if continual burials were severe. Moreover, the delayed germination and emergence would increase the chances of infection by seed-borne and sediment-borne pathogens, and thus greatly decreased seedling emergence (FinchSavage, 1995). Although there was a small percentage of seedlings emerged from $10 \mathrm{~cm}$ continual burial depth, the maximum emergence depth of $S$. salsa in the field conditions might be less than $10 \mathrm{~cm}$ due to its rather small seed size and the complex microenvironment factors surrounding the seeds.

This study also indicated that the highest seedling emergence and the shortest emergence time occurred at 2 and $4 \mathrm{~cm}$ burial depths, respectively, which was different to the conclusions reported by most single one-time burial experiments (Table 1 ). In lacustrine marsh, freshwater marsh and coastal marsh ecosystems, the highest emergence generally occurred at sediment surface (0$0.25 \mathrm{~cm}$ ) (Jurik et al., 1994; Leck, 1996; Cheplick and Grandstaff, 1997; Peterson and Baldwin, 2004; Mou and Sun, 2011) if the seeds were affected by one-off burial. Compared to one-off burial, continual burial generally maintains a low-stress environment around seeds, and the seeds may adjust quickly to smaller burial deposits and have enough energy to raise their cotyledons above the sediment (Maun et al., 1996). In this study, the highest seedling emergence and the shortest emergence time occurred at shallow burial depths ( 2 and $4 \mathrm{~cm}$ ). After sowing for 3 days, $31.25 \pm 6.57 \%$ of $S$. salsa seeds at $4 \mathrm{~cm}$ depth germinated, and the ultimate percent emergence at 2 and $4 \mathrm{~cm}$ depths reached $56.00 \pm 6.60 \%$ and $47.50 \pm 5.95 \%$, respectively (Figs. $1-2$ ). The reason might be related to the above-mentioned quick adjustment of seeds and the stimulatory effect triggered by shallow burials. Taken in this sense, it was concluded that the continual burial of $1-2 \mathrm{~mm} \mathrm{~d}^{-1}$ would be favorable for the emergence of $S$. salsa seedlings. Actually, the use of thin-layer deposition of dredged materials to restore degraded wetlands has been practiced (Ford et al., 1999), and our study provided valuable information to improve restoration efforts of degraded S. salsa marsh. Especially, this study provided another way for the restoration of degraded $S$. salsa marsh during the initial stage of seedling establishment. As mentioned previously, although parts of degraded $S$. salsa marsh have been restored during the WSRP, more than $80 \%$ of S. salsa marsh was still in degraded status. In order to increase restoration area, multiple measures should be taken in the next step, and our results laid a good foundation for the scientific decision-making and management of restoration project at a large scale in the Yellow River estuary. Accompanied with freshwater supplementation for degraded $S$. salsa marsh, the application of continual burial $\left(1-2 \mathrm{~mm} \mathrm{~d}^{-1}\right)$ would be more effective for seedling establishment. Although the highest seedling emergence also occurred at shallow burials $(1-2 \mathrm{~cm})$ in lacustrine sand dune ecosystems (Table 1 ), the inherent mechanism might be different. Seeds at the sand surface were generally exposed to higher temperature and lower humidity, while moderate burial might prevent seeds from being exposed to air and maintain higher humidity, which was favorable for seed germination (Maun, 1994).

\subsection{Morphology of seedlings in response to different continual burial depths}

This study showed that continual burial not only increased stem diameter, taproot length, number and length of branch of $S$. salsa seedlings, but also stimulated seedling height growth and dry mass accumulation. These influences would be favorable for maintaining S. salsa populations and encouraging further growth in barren and continual deposition habitats. Although similar conclusions were drawn by some one-off burial experiments which found seedlings (different species) emerging from a deeper location had higher 

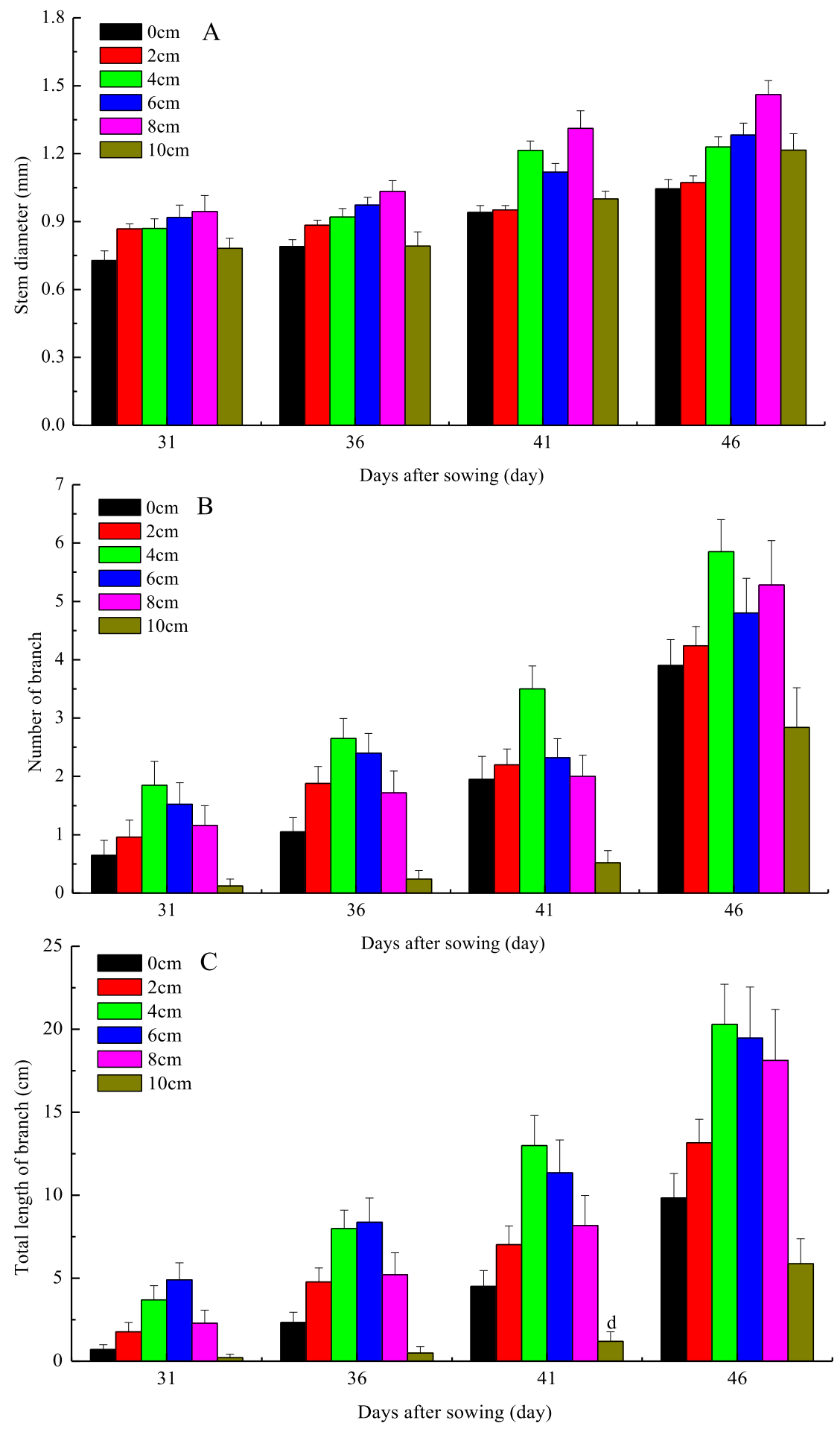

Fig. 5. Mean $( \pm$ SE) stem diameter (A), number (B) and length of branch (C) of seedlings of Suaeda salsa at different continual burial depths.

seedling height, longer first internode or subcoleoptile internode, longer root system and increased dry mass accumulation (Maun and Riach, 1981; Redmann and Qi, 1992), the optimal burial depth was different. Previous studies have demonstrated that, in an optimal range of depth, the stimulatory effects generally increased with increasing depth, while over the range, the promotions disappeared and the inhibiting effects greatly enhanced (Redmann and Qi, 1992; Chen and Maun, 1999; Li et al., 2006). However, our study drew a different result. The stem diameter and taproot length increased with increasing continual burial depths $(0 \sim 8 \mathrm{~cm})$ (Figs. 5A and 6B), while the number and length of branch and the dry mass of seedlings only increased at depths of $0-4 \mathrm{~cm}$ (Figs. 5B,C, 7). These indicated that $4 \mathrm{~cm}$ might be the optimal burial depth for the growth of $S$. salsa seedlings if all the morphological traits were considered. Although the number and length of branch of seedlings emerging from 6 and $8 \mathrm{~cm}$ burial depths did not surpass those from $4 \mathrm{~cm}$ depth due to later emergence, the values were still higher than those from 2 and $10 \mathrm{~cm}$ depths (Fig. 5B,C). A similar 

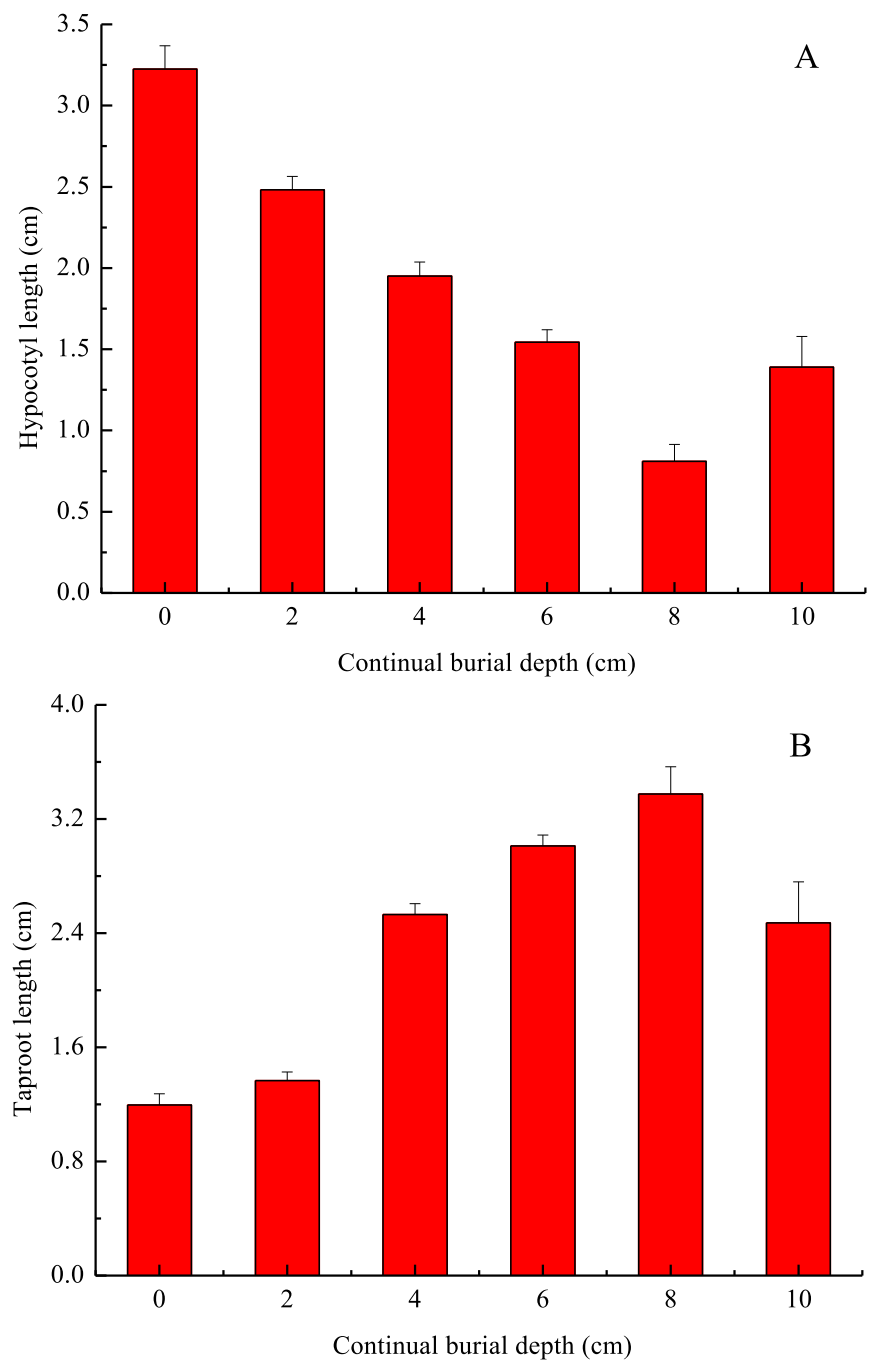

Fig. 6. Mean ( \pm SE) hypocotyl (A) and taproot (B) length of seedlings of Suaeda salsa at different continual burial depths after 46 days.

pattern was also observed in dry mass accumulation. Although the dry mass of seedlings emerging from $6 \mathrm{~cm}$ burial depth did not surpass those from $4 \mathrm{~cm}$ depth, the values were still much higher than those from 2, 8 and $10 \mathrm{~cm}$ depths (Fig. 7). In summary, the stimulatory effects could also be observed at 6 and $8 \mathrm{~cm}$ burial depths though $4 \mathrm{~cm}$ was the optimal burial depth, and there were two possible reasons. First, although continual burial produced a low-stress environment for seedlings, the vigor of seedlings might be triggered by moderate burials ( 6 or $8 \mathrm{~cm}$ ) compared with a oneoff burial of the same magnitude. This was tested by Maun et al. (1996) who found that continual burial of Cirsium pitcheri to 4 or $8 \mathrm{~cm}$ depths produced higher values of most traits than the single burial treatment. The continual burial treatment was more akin to the natural episodes of burial and would allow plants to adapt more quickly than single one-time burial (Lee and Ignaciuk, 1985). Second, S. salsa probably differed from other species in its ability to adapt the rapid and continual deposition conditions in the Yellow River estuary.

Once emerged, successful establishment of seedlings will primarily depend on their ability to rapidly attain sufficient size. In the post-establishment phase, seedling relative growth rate, rather than seedling mass, was the most important determinant of continuing recruitment success (Dalling and Hubbell, 2002). In this study, although seedling heights at $10 \mathrm{~cm}$ burial depth were less

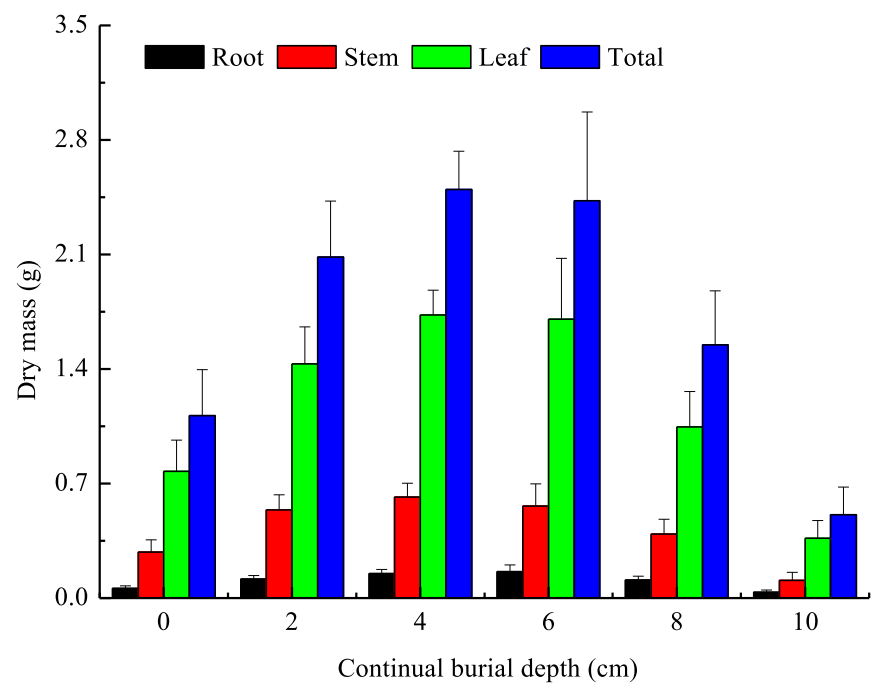

Fig. 7. Mean $( \pm$ SE) dry mass of seedlings of Suaeda salsa at different continual burial depths after 46 days.

than those at other depths (Fig. 3), the highest relative height growth rate occurred at $10 \mathrm{~cm}$ burial depth (Fig. 4B), indicating that seedlings at $10 \mathrm{~cm}$ depth had the highest growth potential. Given favorable conditions and sufficient time, seedlings with higher relative height growth rates (at $10 \mathrm{~cm}$ depth) would surpass seedlings with lower relative height growth rates although they were always the lowest during the experiment. Moreover, this study showed that a significant increase in dry mass of $S$. salsa seedlings occurred at shallow burial depths ( 2 and $4 \mathrm{~cm}$ ), which was probably because of an increase in the growth of roots that provide more nutrients and moderate growth conditions thus increasing the growth of shoots (Perumal and Maun, 2006). Perhaps, the most important factor would be an increase in root mass and the expansion of considerable mycorrhizal fungi into the burial deposit, which would exploit the available resources from the burial deposit, especially nitrogen or phosphorus for the benefit of plants (Koske and Polson, 1984). This study also indicated that, at moderate and deep burial depths $(6,8$ and $10 \mathrm{~cm})$, the dry mass of $S$. salsa seedlings decreased with increasing burial depth though the stimulatory effects still could be observed at 6 and $8 \mathrm{~cm}$ burial depths. The result differed from Maun et al. (1996) who found that, at all continual burial depths (4 and $8 \mathrm{~cm}$ ), the dry mass of C. pitcheri seedlings in Lake Huron increased with increasing burial depth, while at single burial depths, the maximum dry mass occurred at $4 \mathrm{~cm}$ burial depth. There were two possible causes. For one thing, sediment burial mode probably influenced the experimental results. The continual burial modes of our study were $2 \mathrm{~cm}$ $\left(1 \mathrm{~mm} \mathrm{~d}^{-1}\right), 4 \mathrm{~cm}\left(2 \mathrm{~mm} \mathrm{~d}^{-1}\right), 6 \mathrm{~cm}\left(3 \mathrm{~mm} \mathrm{~d}^{-1}\right), 8 \mathrm{~cm}\left(4 \mathrm{~mm} \mathrm{~d}^{-1}\right)$ and $10 \mathrm{~cm}\left(5 \mathrm{~mm} \mathrm{~d}^{-1}\right)$, while those of Maun et al. (1996) were $4 \mathrm{~cm}$ ( $1 \mathrm{~cm}$ every 8 days) and $8 \mathrm{~cm}$ ( $2 \mathrm{~cm}$ every 8 days), implying that the burial in our study produced higher stressful environment for seedlings. For another, as mentioned previously, S. salsa probably differed from other species, which might induce the different response to continual burial depths. The allocation and utilization of resources is a fundamental and vital activity of plants (Zhao et al., 2007). It was also anticipated that dry mass allocation would change with increasing burial depth. This was tested in this experiment. With increasing burial depth, leaf-mass and root-mass ratios increased by $2.50 \%$ and $1.52 \%$, respectively, while stem-mass ratio decreased by $4.01 \%$. The variations of dry mass allocation in different burial treatments indicated that $S$. salsa seedlings could adjust their resources to tolerate different sediment stresses. 
Table 1

Comparison of the optimal burial depths (one-off burial) of seedling emergence in different wetland ecosystems.

\begin{tabular}{|c|c|c|c|c|c|}
\hline Ecosystems & Study sites & Species & Burial depths (cm) & $\begin{array}{l}\text { Optimal } \\
\text { burial } \\
\text { depth }(\mathrm{cm})\end{array}$ & References \\
\hline \multirow[t]{2}{*}{ Lacustrine sand dune } & $\begin{array}{l}\text { Providence Bay, } \\
\text { Manitoulin Island (Canada) }\end{array}$ & Cirsium pitcheri & $2,4,6,8,10,12$ & 2 & Chen and Maun (1999) \\
\hline & $\begin{array}{l}\text { Lake Huron, Pinery } \\
\text { Provincial Park (Canada) }\end{array}$ & Calamovilfa longifolia & $0,1,2,4,6,8,10,12$ & $1-2$ & Maun and Riach (1981) \\
\hline \multirow[t]{2}{*}{ Lacustrine marsh } & Big Wall Lake (Clarion, Iowa, USA) & $\begin{array}{l}\text { Leersia oryzoides, Echinochloa } \\
\text { crusgalli, Typha spp., Carex spp. }\end{array}$ & $0,1,2$ & 0 & Jurik et al. (1994) \\
\hline & Eagle Lake (Britt, Iowa, USA) & $\begin{array}{l}\text { Ricciocarpus natans, } \\
\text { Typha spp., Riccia fluitans, } \\
\text { Ranunculus scleratus L. } \\
\text { Scirpus spp. }\end{array}$ & $0,0.25,0.5,1.0,2.0$ & 0.25 & \\
\hline \multirow[t]{2}{*}{ Freshwater marsh } & $\begin{array}{l}\text { Nanticoke River watershed } \\
\text { (Maryland and Delaware, USA) }\end{array}$ & Leersia oryzoides, Typha spp. & $0,0.25,0.5,1.0,2$ & 0 & Peterson and Baldwin (2004) \\
\hline & Delaware River (USA) & $\begin{array}{l}\text { Bidens laevis, Impatiens capensis, } \\
\text { Peltandra virginica, } \\
\text { Phalaris arundinacea }\end{array}$ & $0,1,5$ & 0 & Leck (1996) \\
\hline \multirow[t]{2}{*}{ Coastal marsh } & Midland Beach, Staten Island (USA) & Triplasis purpurea & $0,3,6$ & 0 & Cheplick and Grandstaff (1997) \\
\hline & Yellow River estuary (China) & Suaeda salsa & $0,1,2,3,4,5,6,8$ & 0 & Mou and Sun (2011) \\
\hline
\end{tabular}

Similar result was also reported by Maun et al. (1996) who found that the root to shoot ratio of $C$. pitcheri seedlings changed greatly with increasing continual burial/one-off burial depth. Yang et al. (2007) and Chen et al. (2011) also indicated that both the dry mass allocation of Bromus inermis and Hedysarum scoparium seedlings were greatly altered with increasing burial depth. The $B$. inermis seedlings emerging from deep burial showed greater biomass allocation to aboveground parts, while $H$. scoparium seedlings allocated more biomass to belowground part. In this study, the dry mass allocation to roots changed insignificantly, which was dependent on the lower root dry mass compared to the total dry mass of seedlings. The increase of allocation to leaves and the decrease of allocation to stems were related to the resource allocation of seedlings after emerging from different depths. In order to survive the continual burial episode, $S$. salsa seedlings must allocate more resources and energy to leaf development, which was favorable for emerging from the burial deposit and then rapidly reinstated photosynthetic activity (Perumal and Maun, 2006). Similar conclusions were drawn by Harris and Davy $(1987,1988)$ who found that, in order to maintain photosynthetic capacity, Elymus farctus seedlings buried in sand allocated more biomass and nutrients to aboveground parts.

Theoretically, the length of hypocotyl is greatly longer in seedlings that have emerged from seeds sown at greater depths of planting, and it has been tested by some previous studies (Maun and Lapierre, 1986; Chen and Maun, 1999). However, our study drew a different result. At depths of $0-8 \mathrm{~cm}$, the deeper the burial depth, the shorter the seedling hypocotyl (Fig. 6A) and the longer the seedling taproot (Fig. 6B). Since seedling hypocotyl generally responded to being underground by developing adventitious roots on the lower part, the variations of the length of seedling hypocotyl and taproot might be dependent on the formation mechanism of adventitious roots. The root-stem transition zone was generally higher in deep burial treatments, which could better explain the decrease in hypocotyl length and the increase in taproot length with burial depths (Mou and Sun, 2011). Actually, at the end of the experiment, we indeed found that part of the hypocotyls below the sediment developed into adventitious roots. The reason for the formation of adventitious roots might be related to the anaerobic condition caused by continual sediment burial. Jackson (1985) indicated that anaerobic conditions were favorable for the formation of adventitious roots and aerenchyma of salt-tolerant plants. The formation of developed root system would be of adaptive significance in coastal marsh because it not only prevented $S$. salsa from being scoured by tides or buried by sediment, but also promoted seedlings to acquire more nutrients from sediment to support shoot growth. Thus, we could easily explain why there was a stimulatory effect on height, stem diameter, number and length of branch, taproot length and dry mass of seedlings of $S$. salsa at shallow and moderate burials. Comparatively, the length of hypocotyl at $10 \mathrm{~cm}$ burial depth was longer than that at $8 \mathrm{~cm}$ depth (Fig. 6A) while the length of taproot at $10 \mathrm{~cm}$ burial depth was shorter than that at $8 \mathrm{~cm}$ depth (Fig. 6B), implying that, at deep burial, only small proportion of hypocotyls below the sediment developed into adventitious roots and $8 \mathrm{~cm}$ might be the optimal burial depth for the formation of adventitious roots. In summary, the formation of adventitious roots in the hypocotyl below the sediment was very important for the growth of seedlings, suggesting that $S$. salsa seedlings might have a special adaptive strategy in response to the rapid and dynamic burial environment in the coastal marsh of the Yellow River estuary.

\section{Acknowledgments}

The authors would like to acknowledge the two anonymous reviewers for their constructive comments on this paper. This study was financially supported by the "1-3-5" Strategy Plan Program of the Yantai Institute of Coastal Zone Research of the Chinese Academy of Sciences (No. Y254021031), the National Nature Science Foundation of China (No. 41171424, 41371104), the Key Research Program of the Chinese Academy of Sciences (No. KZZD-EW-14), the Nature Science Foundation of Shandong Province (No. ZR2013CQ007), and the Talents Program of the Youth Innovation Promotion Association, Chinese Academy of Sciences (No. Y129091041).

\section{References}

Baldwin, K.A., Maun, M.A., 1983. Microenvironment of Lake Huron sand dunes. Can. J. Bot. 61, 241-255.

Chandrasekaral, W.U., Frid, C.L.J., 1998. A laboratory assessment of the survival and vertical movement of two epibenthic gastropod species, Hydrobia. J. Exp. Mar. Biol. Ecol. 221, 191-207.

Chen, W., Wang, J.H., Zhang, Y., Qiang, X.X., 2011. Effect of sand burial depth on seedling emergence and growth of Hedysarum scoparium. Ecol. Sci. 30 (1), 2631.

Chen, H., Maun, M.A., 1999. Effects of sand burial depth on seed germination and seedling emergence of Cirsium pitcheri. Plant Ecol. 140, 53-60.

Cheplick, G.P., Grandstaff, K., 1997. Effects of sand burial on purple sandgrass (Triplasis purpurea):the significance of seed heteromorphism. Plant Ecol. 133, 7989. 
Cui, B.S., He, Q., Zhao, X.S., 2008. Response on the ecological thresholds of Suaeda salsa to the environmental gradients of water table depth and soil salinity. Acta Ecol. Sin. 28 (4), 1408-1418.

Cui, B.S., Yang, Q.C., Yang, Z.F., Zhang, K.J., 2009. Evaluating the ecological performance of wetland restoration in the Yellow River Delta, China. Ecol. Eng. 35, 1090-1103.

Dalling, J.W., Hubbell, S.P., 2002. Seed size, growth rate and gap microsite conditions as determinants of recruitment success for pioneer species. J. Ecol. 90 $557-568$.

Deng, Z.F., An, S.Q., Zhao, C.J., Chen, L., Zhou, C.F., Zhi, Y.B., Li, H.L., 2008. Sediment burial stimulates the growth and propagule production of Spartina alterniflora Loisel. Estuar. Coast. Shelf S 76, 818-826.

Disraeli, D.J., 1984. The effect of sand deposits on the growth and morphology of Ammophila breviligulata. J. Ecol. 72, 145-154.

Finch-Savage, W.E., 1995. Influence of seed quality on crop establishment, growth, and yield. In: Basra, A.S. (Ed.), Seed Quality: Basic Mechanisms and Agricultura Implications. Food Products Press, New York, pp. 361-384.

Ford, M.A., Cahoon, D.D., Lynch, J.C., 1999. Restoring marsh elevation in a rapidly subsiding salt marsh by thin layer deposition of dredged material. Ecol. Eng. 12 $189-205$.

Gu, F.T., 1998. Research in exploiting the green series of edibles-Suaeda salsa. J. Binzhou Edu. Coll. 5, 43-48.

Harper, J.L., Benton, R.A., 1966. The behavior of seeds in soil. The germination of seeds on the surface of a water supplying substrate. J. Ecol. 54, 151-156.

Harris, D., Davy, A.J., 1987. Seedling growth in Elymus farctus after episodes of burial with sand. Ann. Bot-Lond. 60, 587-593.

Harris, D., Davy, A.J., 1988. Carbon and nutrient allocation in Elymus farctus seedlings after burial with sand. Ann. Bot-Lond. 61, 147-157.

Huang, Z.Y., Dong, M., Gutterman, Y., 2004. Factors influencing seed dormancy and germination in sand, and seedling survival under desiccation, of Psammochloa villosa (Poaceae), inhabiting the moving sand dunes of Ordos, China. Plant Soil 259, 231-241.

Jackson, M.B., 1985. Ethylene and response of plants to soil waterlogging and submergence. Ann. Rev. Plant Physio. 36, 145-175.

Jurik, T.W., Wang, S.C., van der Valk, A.G., 1994. Effects of sediment load on seedling emergence from wetland seed banks. Wetlands 14, 159-165.

Koske, R.E., Polson, W.R., 1984. Are VA mycorrhizae required for sand dune stabilization? Bioscience 34, 420-424.

Leck, M.A., 1996. Germination of macrophytes from a Delaware river tidal fresh wetland. Bull. Torrey Bot. Club 123, 1547-1557.

Lee, J.A., Ignaciuk, R., 1985. The physiological ecology of strandline plants. Vegetatio 62, 319-326.

Lee, S.K., Tan, W.H., Havanond, S., 1996. Regeneration and colonization of mangrove on clay-filled reclaimed land in Singapore. Hydrobiologia 319, 23-35.

Leishman, M.R., Westoby, M., 1994. The role of large seeds in seedling establishment in dry soil conditions-experimental evidence from semi-arid species. J. Ecol. 82, $249-258$.

Li, Q.Y., Zhao, W.Z., Fang, H.Y., 2006. Effects of sand burial depth and seed mass on seedling emergence and growth of Nitraria sphaerocarpa. Plant Ecol. 185, $191-$ 198.

Li, S.H., Zhou, D.M., Luan, Z.Q., Pan, Y., Jiao, C.C., 2011. Quantitative simulation on soil moisture contents of two typical vegetation communities in Sanjiang Plain, China. Chin. Geogra. Sci. 22 (6), 723-733.

Li, Y.F., Huang, Y.L., Li, S.K., 1991. A primarily analysis on the coastal physiognomy and deposition of the modern Yellow River Delta. Acta Oceanol. Sin. 13 (5), 662-671.

Maun, M.A., 1994. Adaptation enhancing survival and establishment of seedlings on coastal dune systems. Vegetatio 111, 59-70.

Maun, M.A., 1998. Adaptations of plants to burial in coastal sand dunes (1997 George Lawson Medal Review). Can. J. Bot. 76, 713-738.
Maun, M.A., Elberling, H., D'Ulisse, A., 1996. The effects of burial by sand on survival and growth of Pitcher's thistle (Cirsium pitcheri) along Lake Huron. J. Coast. Conserv. 2, 3-12.

Maun, M.A., Lapierre, J., 1986. Effects of burial by sand on seed germination and seedling emergence of four dune species. Am. J. Bot. 73 (3), 450-455.

Maun, M.A., Riach, S., 1981. Morphology of caryopses, seedlings and seedling emergence of the grass Calamovilfa longifolia from various depths in sand. Oecologia 49, 142-167.

Mou, X.J., 2010. Study on the Nitrogen Biological Cycling Characteristics and Cycling Model of Tidal Wetland Ecosystem in Yellow River Estuary. Master degree dissertation. Yantai Institute of Coastal Zone Research, Chinese Academy of Sciences, Yantai.

Mou, X.J., Sun, Z.G., 2011. Effects of sediment burial disturbance on seedling emergence and growth of Suaeda salsa in the tidal wetlands of the Yellow River estuary. J. Exp. Mar. Biol. Ecol. 409, 99-106.

Perry, D.A., 1984. Factors influencing the establishment of cereal crops. Asp. Appl. Biol. 7, 65-83.

Perumal, V.J., Maun, M.A., 2006. Ecophysiological responses of dune species to experimental burial under field and controlled conditions. Plant Ecol. 184, 89-104.

Peterson, J.E., Baldwin, A.H., 2004. Seedling emergence from seed banks of tidal freshwater wetlands: response to inundation and sedimentation. Aquat. Bot. 78, $243-254$.

Redmann, R.E., Qi, M.Q., 1992. Impacts of seeding depth on emergence and seedling structure in eight perennial grasses. Can. J. Bot. 70, 133-139.

Sun, Z.G., Mou, X.J., Sun, J.K., Song, H.L., Yu, X., Wang, L.L., Jiang, H.H., Sun, W.L., Sun, W.G., 2012. Nitrogen biological cycle characteristics of seepweed (Suaeda salsa) wetland in intertidal zone of Huanghe (Yellow) River estuary. Chin. Geogra. Sci. 22 (1), 15-28.

Terrados, J., Tampahnya, U., Srichai, N., Kheowvongsri, P., Geertz-Hansen, O., Boromthanarath, S., Panapitukkul, N., Duarte, C.M., 1997. The effect of increased sediment accretion on the survival and growth of Rhizophora apiculata seedlings. Estuar. Coast. Shelf S 45, 697-701.

Thampanya, U.T., Vermaat, J.E., Terrados, J.T., 2002. The effect of increasing sediment accretion on the seedlings of three common Thai mangrove species. Aquat. Bot. 74, 315-325.

van der Valk, A.G., 1974. Environmental factors controlling the distribution of forbs on coastal foredunes in Cape Hatteras National Seashore. Can. J. Bot. 52, 1057-1073.

Weis, I.M., 1982. The effects of propagule size on germination and seedling growth in Mirabilis hirsuta. Can. J. Bot. 60, 1868-1874.

Weller, S.G., 1985. Establishment of Lithospermum caroliniense on sand dunes: the role of nutlet mass. Ecology 66, 1893-1901.

Wen, B.L., Liu, X.T., Li, X.J., Yang, F.Y., Li, X.Y., 2012. Restoration and rational use of degraded saline reed wetlands: a case study in western Songnen Plain, China. Chin. Geogra. Sci. 22 (2), 167-177.

Xu, X.G., Guo, H.H., Chen, X.L., Lin, H.P., Du, O.L., 2002. A multi-scale study on land use and land cover quality change: the case of the Yellow River Delta in China. GeoJournal 56 (3), 177-183.

Yanful, M., Maun, M.A., 1996. Effects of burial of seeds and seedlings from different seed sizes on the emergence and growth of Strophostyles helvola. Can. J. Bot. 74, $1322-1330$

Yang, H.L., Cao, Z.P., Dong, M., Ye, Y.Z., Huang, Z.Y., 2007. Effects of sand burying on caryopsis germination and seedling growth of Bromus inermis Leyss. Chin. J. Appl. Ecol. 18 (11), 2438-2443.

Zhang, J., Maun, M.A., 1990. Sand burial effects on seed germination, seedling emergence and establishment of Panicum virgatum. Holarct. Ecol. 13, 56-61.

Zhang, J., Maun, M.A., 1994. Potential for seed bank formation in seven Great Lakes sand dune species. Am. J. Bot. 81, 387-394.

Zhao, W.Z., Li, Q.Y., Fang, H.Y., 2007. Effects of sand burial disturbance on seedling growth of Nitraria sphaerocarpa. Plant Soil. 295, 95-102. 